\title{
Sustaining Student Gains From Online On-Demand Professional Development
}

\author{
Steven H. Shaha, PhD, DBA, University of Utah, USA \\ Kelly Glassett, PhD, University of Utah, USA \\ Aimee Copas, PhD, Executive Director, North Dakota Council of Educational Leaders, USA
}

\begin{abstract}
A multi-State, quasi-experimental study was conducted as a longitudinal, two-year follow-up of participation in an online, on-demand professional development (PD) program. The purpose was to ascertain whether student gains were sustained in a second year of PD participation. Data verified gains in Year 1 versus Pre-PD baseline, with continued gains in Year 2 atop those achieved in year 1 of PD participation, reflecting a positive trend and continued advantage over non-PD schools in the same districts. Results showed that student in PD schools gained $7.7 \%$ ( $p<.01)$ more in Math in year 2 atop 18.9\% ( $p<.001)$ gains from year 1, versus gains of 0.5\% (ns) and $4.2 \%$ ( $p<.01)$ for non-PD schools in the same districts. Similarly, students in the PD schools gained $10.2 \%$ ( $p<.01)$ more in Reading in year 2 atop $18.9 \%$ ( $p<.001)$ gains from year 1 , versus gains of $0.5 \%(n s)$ and $4.2 \%$ ( $p<.01)$ for non-PD schools in the same districts. Total gains from baseline for PD schools were $28.1 \%$ ( $p<0.001)$ in Math for PD schools versus $4.7 \%(p<0.01)$ for the same districts collectively, and 30.2\% ( $p<0.001)$ in Reading for PD schools versus $6.0 \%$ $(p<0.01)$ for the same districts collectively. Findings support the high-participation use of Internet-based, on-demand professional learning for improving teacher effectiveness and sustained impacts on student performance.
\end{abstract}

Keywords: Professional Development; On-Demand Professional Learning; Professional Development

\section{INTRODUCTION}

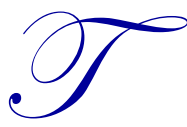

he main purpose of professional development (PD) remains primarily to improve the impact teachers have on their students (Borko, 2004; Fishman et.al., 2003; Guskey, 2002; Loucks-Horsley et.al., 2009; Mizell, 2010; Shaha et.al., 2004; Villegas-Reimers, 2003; Wilson \& Berne, 1999). Many PD approaches provide teachers with an opportunity for time off from the classroom routine to participate in PDfocused workshop and seminar settings. The advent of video-enabled PD approaches began to provide educators the ability to obtain access to PD in smaller portions without costly absences from day-to-day classroom settings (Colestock \& Sherin, 2009; Ingvarson et al. 2005; Sherin \& van Es, 2005, 2009). Avoiding removal of teachers for PD thus reduced the cost of PD in terms of teacher replacement, but also provided needed or wanted PD training with immediate applicability.

More recently, advances in technology have enabled teachers to access PD through online, on-demand, and Internet based offerings. These offerings have evolved to reflect our increased understanding of how teachers can best learn about teaching, and teaching better, have advanced (Bahr et al., 2004; Borko, 2004; Ingvarson et al. 2005; Putnam \& Borko, 2000). They also make possible levels of selectivity in teacher participation enabling more personally relevant selections and participation (Shaha et al. 2014). As a result, the expectations of PD offerings have progressed (Sherin \& Han, 2004; Sherin \& van Es, 2005, 2009).

Regardless of improved understanding of how teachers learn, and better Internet-based delivery options, studies quantifying and validating the impact of PD on student performance have remained rare at best (c.f. Shaha et.al., 2004). Masters, et.al., commented specifically on this "dearth of scientific research" (Masters et al. 2012). 
Such is a travesty, given the pressure on administrators and educators to improve the impact teachers have on students. Decisions regarding PD expenditures and participation remain based primarily on marketing and reputation, and not on statistically rigorous, data-rich studies. However, as the costs associated with providing educational offerings are more rigorously scrutinized into the future, the need to prove PD impact will become increasingly important (Farnsworth et al. 2002; Lewis et al. 2003; Magidin et al. 2012; Rienties et al. 2013). Substantially more research is needed to establish quantitatively a compelling link between teacher participation in PD and gains in student performance (Garet et al. 2001; Desimone et al. 2002; Shaha et al. 2004; Ingvarson et al., 2005; Buczynski \& Hansen 2010; Avalos 2011).

In the interest of verifying the impact of PD participation, two important trends are recently materializing. First, a handful of studies have emerged that add substance to arguments that applying rigorous program evaluation designs and techniques to PD offerings is increasingly necessary and valid to meet the needs for increased accountability for ensuring that PD expenditures reflect investments (c.f. Shaha et. al. 2004; Shaha \& Ellsworth, 2013). Second, additional recent studies have shown that quantifying improvements in student performance on standardized tests provides a legitimate, rigorous and generalizable approach to validating value (Buczynski and Hansen 2010; Avalos 2011; Garet et al. 2001; Desimone et al. 2002; Ingvarson et al. 2005; Wasik \& Hindman 2011). Thus the measure of teacher impact on students as enhanced through PD participation has leveraged scores as a useful metric for assessing and quantifying impact.

Reflecting the evolution of PD, studies related to PD delivered online and on-demand have recently increased (c.f. Shaha \& Ellsworth 2013). Studies have logically verified that the level of teacher activity and engagement with online PD affects the correlated impact achieved for student performance - students of teachers with highly active engagement in online PD outpaced the students of teachers reflecting more passive PD participation, such as viewing videos alone, versus downloading and uploading material (Garet et al. 2001; Desimone et al. 2002; King 2002; Darling-Hammond 2004; Santagata, 2009; Shaha \& Ellsworth 2013).

The purpose of this research was to perform a longitudinal, two-year follow-up study leveraging a multiState, quasi-experimental design. The study will reflect the comparative impact of PD on the students of participating teachers versus comparable, non-participating schools within same districts. We built upon the findings of a one-year, pre-versus-post, quasi-experimental study formerly published and conducted a second year follow-up (Shaha \& Ellsworth, 2013). Our goal was to determine whether advances experienced for students in their second year of PD participation experienced similar gains as were quantified in the first pre-versus-post year, or whether those early gains diminished or were improved upon.

\section{METHODS}

The study contrasted gains in performance for schools whose teachers participated in the online, ondemand PD offering (hereafter schools) versus the remaining schools in the same district whose teachers did NOT participate (hereafter districts). Additionally, this study was an extension of a previously executed pre-versus-post study, and involved the addition of a second post-implementation year of data to the previously analyzed data (Shaha \& Ellsworth, 2013). The schools and districts included in analyses are the same with the additional year of data added for examining sustainment.

The study design reflected a quasi-experimental approach (Cook \& Campbell 1979): Pre-PD levels of student performance were compared with Year 1 and Year 2 post-implementation. By design, performance in PDparticipating schools was contrasted with that for their own corresponding districts, including mainly nonparticipating schools. Contrasting participating schools with their own districts controlled for socio-economic and demographic differences. Thus findings would not be attributed to demographic or socio-economic differences between groups, or even to general capabilities of either teachers or students - schools and districts represent interchangeable groups in a design.

School participation was defined as use of a single commercially available online, on-demand PD product widely used in the United States (PD 360 ® and Observation 360 ®, School Improvement Network, Salt Lake City). The enabled teachers to participate in a full range activities which range instructional videos on teaching techniques, 
to communities of other users, to posting and downloading PD-related materials. Inclusion criteria for schools was defined as a minimum average of 90 minutes per teacher of logged-in time cumulatively school-wide - this minimum adopted to ensure sufficient PD use to enable that conclusions be drawn regarding the impact of PD use beyond mere sign-on alone or minimal usage. Comparison Further, schools were included along with their corresponding districts only if fewer than $25 \%$ of schools within a given district were categorized as PD participants and met inclusion criteria.

PD school participation data analyzed were extracted from the data automatically captured by the PD provider (School Improvement Network) as a result of PD use, and corresponding district data from the same sources, including verification off eligibility for district meeting non-PD participation criteria. The pre-PD included data from the 2009-2010 school year, and the two post-implementation years - 2010-11 and 2011-12 - were the corresponding data from the subsequent two school years thereafter.

Student performance data were gathered from publically available web sources for the three consecutive school years. Any data not available online were gathered by telephone requests, all with Institutional Review Board (IRB) approval where such existed. For analyses, student performance data were defined as the sum of the percentages of students rated either Proficient or Advanced on the respective standardized student performance tests for each school - no changes in testing were noted within the sample for the three consecutive years of data. Schools and districts included were engaged in performance tests for which Proficient and Advanced were common labels or levels of achievement above other levels indicating performance at grade level or below for that assessment instrument. District data could not be recomputed with exclusion of participating schools, and therefore some changes in performance for the collective districts do reflect changes in performance for the participating schools within.

The final data set included the same 169 schools in 73 districts and 19 States for the third year of data as was analyzed in the previous 2-year pre-versus-post study. All percent changes reported were calculated as net change in performance, divided by performance for the earlier of the two years: e.g. (Year 2 - Year 1)/ Year 1. Effect size was computed using Cohen's $f^{2}$ (Cohen, 1992). Significance for percent change figures was determined by contrasting versus zero change $(0.0 \%)$ by a t-Test for proportions (Rice, 2006). All analyses were conducted using SPSS version 17.0 or higher (PASW Statistics, SPSS, 2009, with SAS for confirmatory purposes when results were close to $\mathrm{p}<0.05$ ). Minimum level of statistical significance was determined a priori at $\mathrm{p}<0.05$.

\section{RESULTS}

\section{Mathematics}

Year 1 of PD Participation

Student performance levels were contrasted for schools versus districts, for pre-PD versus Year 1 post-PD (See Table 1, Figures 1, Shaha \& Ellsworth, 2013). For Math, results showed that students of teachers in PDinclusion schools experienced a net change of 11.1 percentage points in students classified as Proficient or Advanced versus a 2.6 net change for districts. That difference within schools equated to an $18.9 \%(\mathrm{p}<0.001)$ increases in performance year-over-year for PD participation, versus $4.2 \%(\mathrm{p}<0.01)$ comparative increase for districts. The percent change within PD schools was 4.2 times greater than for their respective districts. The effect size for schools was 0.54 , which is 4.15 times greater than the effect size of 0.13 for the districts. Performance within district was marginally better than for schools in the pre-PD year $(\mathrm{p}=0.065)$, and that pattern was reversed for Year 1 post implementation wherein schools were marginally better $(\mathrm{p}=0.085)$. 
Table 1. Student Math performance for participating schools versus their districts

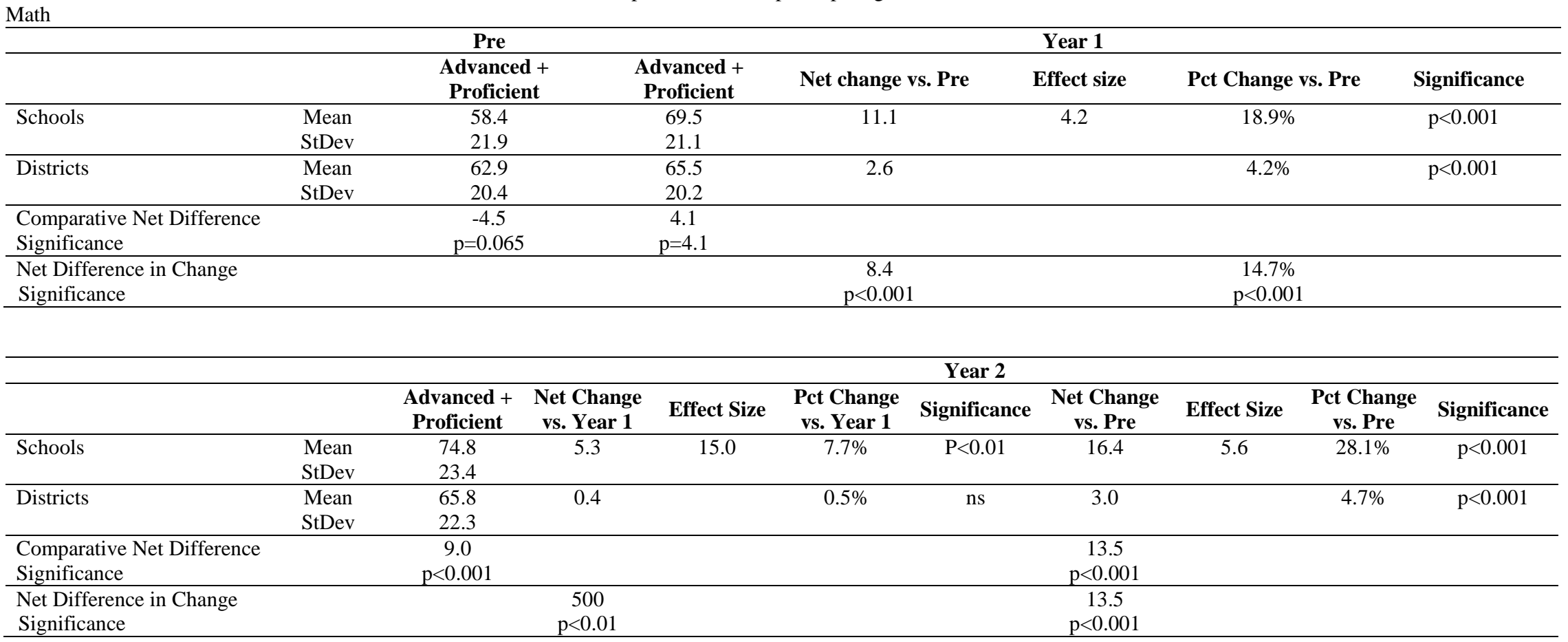


Figure 1. Comparative pre versus post performance for Math proficient and advanced

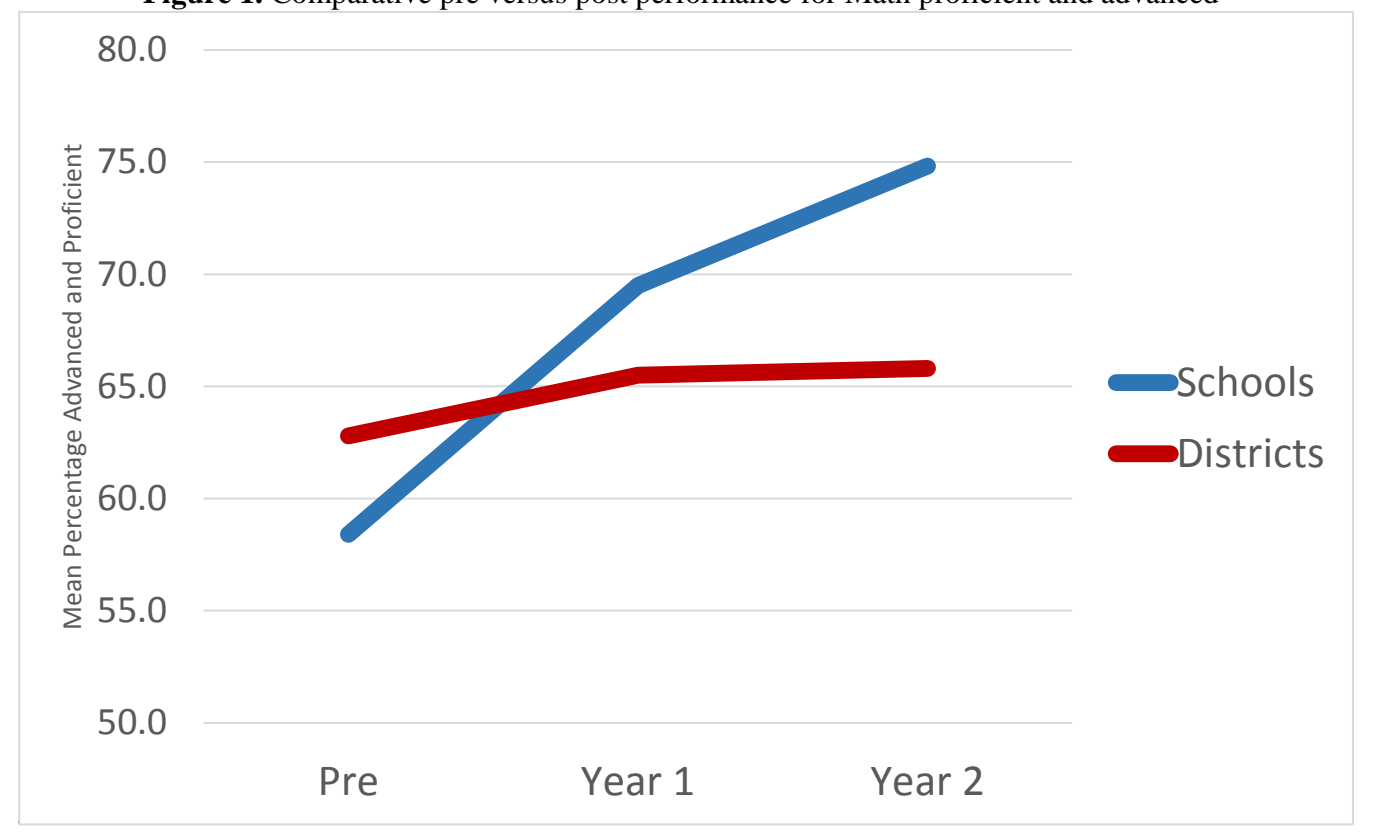

Year 2 of PD Participation

Student performance was contrasted for schools versus districts for gains Post-PD between Year 1 and Year 2. Students of teachers in PD-inclusion schools experienced a second-year net performance improvement of 5.3 percentage points, versus a 0.4 net change for their respective districts. That equaled a $7.7 \%(p<0.01)$ increase in performance year-over-year for schools, versus $0.5 \%$ increase for the districts (not significant, hereafter "ns"). The improvement within schools was 15.5 times greater than for their districts. The effect size for schools was 0.24 , over 17 times greater than the 0.01 effect size for the districts. Performance within schools maintained and increased the advantage established in Year 1 over their district.

\section{Two Years of PD Participation}

Finally, results showed that students in the school group experienced a net performance improvement of 16.4 percentage points when contrasting Year 2 with the pre-PD baseline, versus a 3.0 net change for districts. That equaled a $28.1 \%(\mathrm{p}<0.001)$ increase in performance for schools by Year 2 over baseline, versus $4.7 \%(\mathrm{p}<0.01)$ increase for their respective districts. The growth for students in PD schools was 5.6 times greater than for their respective districts. The two-year effect size for schools was $0.74,5.29$ times greater than the 0.14 two-year effect size for the districts.

\section{Reading}

\section{Year 1 of PD Participation}

Contrasts were performed for student school performance levels for pre-PD versus Year 1 post-PD versus districts (See Table 1, Figures 1, Shaha \& Ellsworth, 2013). Results showed that students in PD schools experienced a net change of 10.3 percentage points in Proficient plus Advanced versus a 1.6 net change for the corresponding districts. That difference within schools equated to an $18.1 \%(\mathrm{p}<0.001)$ increase in performance year-over-year for PD participation, versus $2.6 \%(\mathrm{p}<0.01)$ comparative increase for their districts. The percent change within PD schools was 6.4 times greater than for their respective districts. The effect size for schools was $0.45,6.34$ times greater than the effect size of 0.07 for the districts. Performance within district was marginally better than for schools in the pre-PD year $(\mathrm{p}=0.079)$, and that pattern was reversed for Year 1 post implementation wherein schools were marginally better $(\mathrm{p}=0.063)$. 
Table 2. Student Reading performance for participating schools versus their districts

Reading

\begin{tabular}{|c|c|c|c|c|c|c|c|c|c|c|}
\hline & \multicolumn{4}{|c|}{ Pre } & \multicolumn{3}{|r|}{ Year 1} & \multirow{2}{*}{$\begin{array}{c}\text { Pct Change vs. } \\
\text { Pre }\end{array}$} & \multirow{2}{*}{\multicolumn{2}{|c|}{ Significance }} \\
\hline & & $\begin{array}{c}\text { Advanced } \\
\text { Proficient }\end{array}$ & & $\begin{array}{l}\text { Advanced + } \\
\text { Proficient }\end{array}$ & $\begin{array}{c}\text { Net Change } \\
\text { Pre }\end{array}$ & vs. & ffect Size & & & \\
\hline \multirow[t]{2}{*}{ Schools } & Mean & 56.9 & & 67.2 & 10.3 & & 6.4 & $18.1 \%$ & & $\mathrm{p}<0.001$ \\
\hline & StDev & 22.4 & & 22.1 & & & & & & \\
\hline \multirow[t]{2}{*}{ Districts } & Mean & 61.2 & & 62.7 & 1.6 & & & $2.6 \%$ & & $\mathrm{p}<0.01$ \\
\hline & StDev & 21.1 & & 20.7 & & & & & & \\
\hline $\begin{array}{l}\text { Comparative Net Dif } \\
\text { Significance }\end{array}$ & & $\begin{array}{c}-4.3 \\
p=0.079\end{array}$ & & $\begin{array}{c}4.5 \\
p=0.063\end{array}$ & & & & & & \\
\hline \multirow[t]{3}{*}{$\begin{array}{l}\text { Net Difference in Change } \\
\text { Significance }\end{array}$} & & & & & $\begin{array}{c}8.7 \% \\
p<0.001\end{array}$ & & & $\begin{array}{l}15.5 \% \\
p<0.001\end{array}$ & & \\
\hline & & & & & & Year 2 & & & & \\
\hline & & $\begin{array}{c}\text { Advanced + } \\
\text { Proficient }\end{array}$ & $\begin{array}{l}\text { Net Change } \\
\text { vs. Year } 1\end{array}$ & Effect Size & $\begin{array}{l}\text { Pct Change } \\
\text { vs. Year } 1\end{array}$ & Significance & $\begin{array}{c}\text { Net Change } \\
\text { vs. Pre }\end{array}$ & Effect Size & $\begin{array}{l}\text { Pct Change } \\
\text { vs. Pre }\end{array}$ & $\overline{\text { e Significance }}$ \\
\hline Schools & $\begin{array}{l}\text { Mean } \\
\text { StDev }\end{array}$ & $\begin{array}{l}74.1 \\
19.9\end{array}$ & 6.9 & 3.2 & $10.2 \%$ & $\mathrm{p}<0.001$ & 17.2 & 4.7 & $30.2 \%$ & $\mathrm{p}<0.001$ \\
\hline Districts & $\begin{array}{l}\text { Mean } \\
\text { StDev }\end{array}$ & $\begin{array}{l}64.9 \\
17.4\end{array}$ & 2.2 & & $3.5 \%$ & $\mathrm{p}<0.01$ & 3.7 & & $6.0 \%$ & $\mathrm{p}<0.01$ \\
\hline $\begin{array}{l}\text { Comparative Net Dif } \\
\text { Significance }\end{array}$ & & $\begin{array}{c}9.2 \\
\mathrm{p}<0.001\end{array}$ & & & & & $\begin{array}{c}13.5 \\
\mathrm{p}<0.001\end{array}$ & & & \\
\hline $\begin{array}{l}\text { Net Difference in Change } \\
\text { Significance }\end{array}$ & & & $\begin{array}{c}4.7 \\
p<0.01\end{array}$ & & & & $\begin{array}{c}13.5 \\
\mathrm{p}<0.001\end{array}$ & & & \\
\hline
\end{tabular}


Figure 2. Comparative pre versus post performance for Reading proficient and advanced

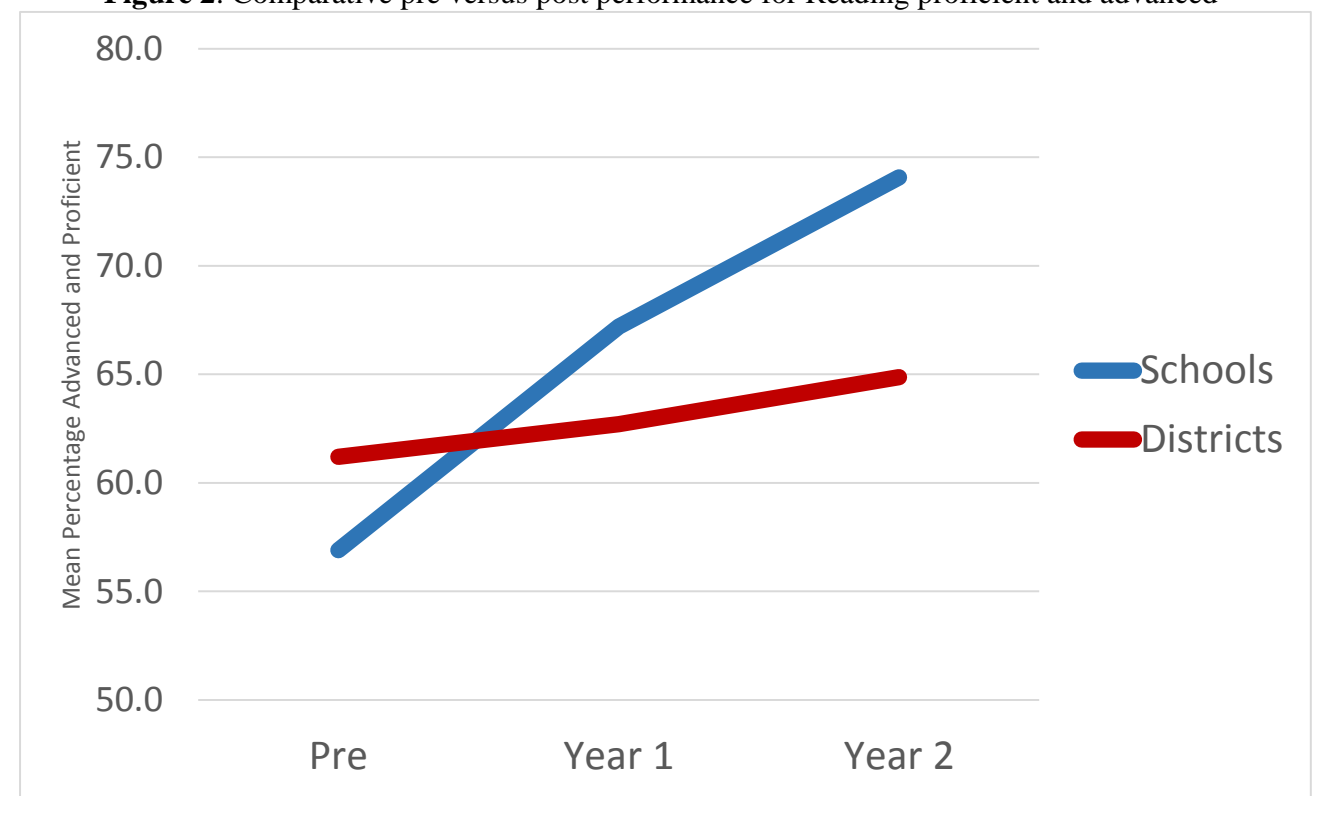

Year 2 of PD Participation

Student performance was next contrasts for Year 1 and Year 2 of PD participation. Students in PDparticipation schools experienced a second-year net performance improvement of 6.9 percentage points over Year 1, versus a 2.2 net change for their respective districts. That equaled a $10.2 \%(\mathrm{p}<0.001)$ increase in performance yearover-year for schools, versus $3.5 \%$ increase for the districts $(\mathrm{p}<0.01)$. The improvement within schools was 3.2 times greater than for their districts. The effect size for schools was $0.32,2.91$ times greater than the 0.11 effect size for the districts.

\section{Two Years of PD Participation}

Lastly, results showed that students in the school group experienced a net performance improvement of 17.2 percentage by Year 2 versus the pre-PD baseline, in contrast with a 3.7 net change for their districts. That equaled a $30.2 \%(\mathrm{p}<0.001)$ increase in performance for schools by Year 2 over baseline, versus $6.0 \%$ ( $p<0.01)$ for their districts. The growth for students in PD schools was 4.7 times greater than for their respective districts. The two-year effect size for schools was $0.81,4.26$ times greater than the 0.19 two-year effect size for the districts.

\section{Asymptotic Pattern}

The graphics depicting the findings for both Mathematics and Reading each portray an important, corroborative, asymptotic pattern. While growth continues in the second year of data, the amount of year-over-year gain decreased versus that achieved in the first year. That continued growth, curving slightly downward year-overyear, represents the ceiling effect $100 \%$ performance represents, wherein schools may incrementally get every-closer to that goal, but cannot exceed it, or possibly achieve it. Statistically, an asymptotic pattern is expected: Levels of students classified as Proficient plus Advanced cannot not exceed 100\%, although that limit can be approached as an ultimate goal.

\section{DISCUSSION AND CONCLUSIONS}

Past research, although limited in volume and rigor, has recently begun to provide some basis for understanding the impact of PD its first year of pre-versus-post implementation. While even less research is available regarding online, on-demand professional development for pre-versus-post interpretation, the body of studies is growing. Despite those advances, still very studies few represent multi-State, high-sample-size analyses 
quantifying PD impact. In that context, still woefully fewer studies exist offering substantive quantitative evidence of the impact of PD into subsequent years as substantiation of sustainment.

We believe this may be the first such study. This multi-state, quasi-experimental study provides quantitate, compelling evidence of the impact of on-demand, Internet-based PD for enhancing teacher efficacy as measured by changes in student performance on standardized tests. First-year post-implementation gains showed that participation in the online, on-demand PD offering resulted in 4.5 times and 6.1 times greater gains for math and reading, respectively, for participating schools versus their respective, comparable district populations. In the second year, advantages were sustained with 5.3 times and 3.2 times greater gains for participating schools versus their district peers. Thus favorable trends persisted, and continued improvements were sustained.

As with all quasi-experimental research, interpretation of these findings involves some extrapolation beyond the ideal controlled conditions of strict experimental research. It remains nearly impossible in education to study comparative student gains within environments with rigorous control-versus-treatment conditions. Therefore it will also remain challenging to firmly establish cause-and-effect conclusions based on the quasi-experimental design and naturalistic settings in which this study was achieved. However, the evidence remains compelling.

Thus this may stand as the first-ever two-year, large sample, follow-up study quantifying the sustained impact of online, on-demand PD on student performance. It surely is one of very, very few studies establishing the sustained effect of any systematic PD on student performance contrasting comparable student populations in a large sample, multi-State design. Bottom line the data clearly and substantively indicate that continued PD participation results in sustained gains, and even continued additional gains, as teachers apparently leverage what they learn. Whether this is explained by acquisition of knowledge and skills from PD participation, or simply improved attention and focus on the part of classroom teachers, will remain unclear. Yet establishing such an explanatory nuance is likely less important than the formulaic conclusion that sustained participation in PD across years is correlated with sustained improvements in student performance.

\section{AUTHOR INFORMATION}

Steven H. Shaha, PhD, DBA, Center for Policy \& Public Administration, University of Utah, 1227 E. Manfield Way, Draper, Utah 84020 USA. Email: steve.shaha@allscripts.com

Kelly Glassett, $\mathrm{PhD}$, University of Utah, $32 \mathrm{~W}$. Center Street, Midvale, 84047, Utah USA. Email: Kelly.glassettimprovement.com

Aimee Copas, PhD, Executive Director, North Dakota Council of Educational Leaders, Utah, USA. Aimee Copas is the executive director of the North Dakota Council of Educational Leaders and Adjunct Professor North Dakota State University, Fargo, ND, USA.

\section{REFERENCES}

Avalos, B. (2011). Teacher professional development in teaching and teacher education over ten years. Teaching and Teacher Education, 27(1), 10-20.

Bahr, D. L., Shaha, S. H., Farnsworth, B. J., Lewis, V. K., \& Benson, L. F. (2004). Preparing tomorrow's teachers to use technology: attitudinal impacts of technology-supported field experience on preservice teacher candidates. Journal of Instructional Psychology, 31(2), 88-97.

Borko, H. (2004). Professional development and teacher learning: Mapping the terrain. Educational researcher, 33(8), 3-15.

Buczynski, S., \& Hansen, C. B. (2010). Impact of professional development on teacher practice: Uncovering connections. Teaching and Teacher Education, 26(3), 599-607.

Colestock, A., \& Sherin, M. G. (2009). Teachers' sense-making strategies while watching video of mathematics instruction. Journal of Technology and Teacher Education, 17(1), 7-29.

Cook, T. D., \& Campbell, D. T. (1979). Quasi-experimentation: Design \& analysis issues for field settings. Boston: Houghton Mifflin Company.

Darling-Hammond, L. (2004). Standards, accountability, and school reform. Teachers College Record, 106(6), 
1047-1085.

Desimone, L. M., Porter, A. C., Garet, M. S., Yoon, K. S., \& Birman, B. F. (2002). Effects of professional development on teacher's instruction: Results from a three-year longitudinal study. Educational Evaluation and Policy Analysis, 24(2), 81-112.

Farnsworth, B., Shaha, S., Bahr, D., Lewis, V., \& Benson. L. (2002). Preparing tomorrow's teachers to use technology: Learning and attitudinal impacts on elementary students. Journal of Instructional Psychology, 29(3).

Fishman, B. J., Marx, R. W., Best, S., \& Tal, R. T. (2003). Linking teacher and student learning to improve professional development in systemic reform. Teaching and teacher education, 19(6), 643-658.

Garet, M. S., Porter, A. C., Desimone, L., Birman, B. F., \& Yoon, K. S. (2001). What makes professional development effective? Results from a national sample of teachers. American Educational Research Journal, 38(4), 915.

Guskey, T. R. (2002). Professional development and teacher change. Teachers and Teaching, 8(3), 381-391.

Ingvarson, L., Meiers, M., \& Beavis, A. (2005) "Factors Affection the Impact of Professional Development Programs on Teachers' Knowledge, Practice, Student Outcomes \& Efficacy" Australian Council for Educational Research. 13(10), January 2005.

King, K. P. (2002). Identifying success in online teacher education and professional development. The Internet and Higher Education, 5(3), 231-246.

Lewis, V. K., Shaha, S. H., Farnsworth, B., Benson, L., \& Bahr, D. (2003). The use of assessment in improving technology-based instruction programs. Journal of Instructional Psychology, 30(2).

Loucks-Horsley, S., Stiles, K. E., Mundry, M. S. E., Love, N. B., \& Hewson, P. W. (2009). Designing professional development for teachers of science and mathematics. Corwin Press.

Magidin, d. K., Masters, J., O'Dwyer, L. M., Dash, S., \& Russell, M. (2012). Relationship of online teacher professional development to seventh-grade teachers' and students' knowledge and practices in English language arts. The Teacher Educator, 47(3), 236-259.

Masters, J., Kramer, R. M. d., O’Dwyer, L., Dash, S., \& Russell, M. (2012). The effects of online teacher professional development on fourth grade students' knowledge and practices in English language arts. Journal of Technology and Teacher Education, 20(1), 21-46.

Mizell, H. (2010). Why Professional Development Matters. Learning Forward (NJ).

Putnam, R. T., \& Borko, H. (2000). What do new views of knowledge and thinking have to say about research on teacher learning? Educational Researcher, 4-15.

Rienties, B., Brouwer, N., \& Lygo-Baker, S. (2013). The effects of online professional development on higher education teachers' beliefs and intentions towards learning facilitation and technology. Teaching and Teacher Education, 29(0), 122-131.

Santagata, R. (2009). Designing video-based professional development for mathematics teachers in low-performing schools. Journal of Teacher Education, 60(1), 38-51.

Shaha SH, Ellsworth H (2013). Multi-State, Quasi-experimental Study of the Impact of On-demand Professional Development on Students Performance. International Journal of Evaluation and Research in Education (IJERE). Vol.2, No. 4.

Shaha, S. H., Lewis, V. K., O'Donnell, T. J., \& Brown, D. H. (2004). Evaluating professional development: An approach in verifying program impact on teachers and students. Journal of Research in Professional Learning, $1(1), 1$.

Sherin, M. G., \& Han, S. Y. (2004). Teacher learning in the context of a video club. Teaching and Teacher Education, 20(2), 163-183.

Sherin, M., \& van Es, E. (2005). Using video to support teachers' ability to notice classroom interactions. Journal of technology and teacher education, 13(3), 475-491.

Sherin, M. G., \& van Es, E. A. (2009). Effects of video club participation on teachers' professional vision. Journal of Teacher Education, 60(1), 20-37.

Wasik, B. A., \& Hindman, A. H. (2011) Improving Vocabulary and Pre-Literacy Skills of at-Risk Preschoolers through Teacher Professional Development. Journal of Educational Psychology 103(2), 455-69.

Wilson, S. M. \& Berne, J. (1999). Teacher learning and the acquisition of professional knowledge: An examination of research on contemporary professional development. Review of Research in Education, 24, 173-209.

Villegas-Reimers, E. (2003). Teacher professional development: an international review of the literature. Paris: International Institute for Educational Planning. 
NOTES 